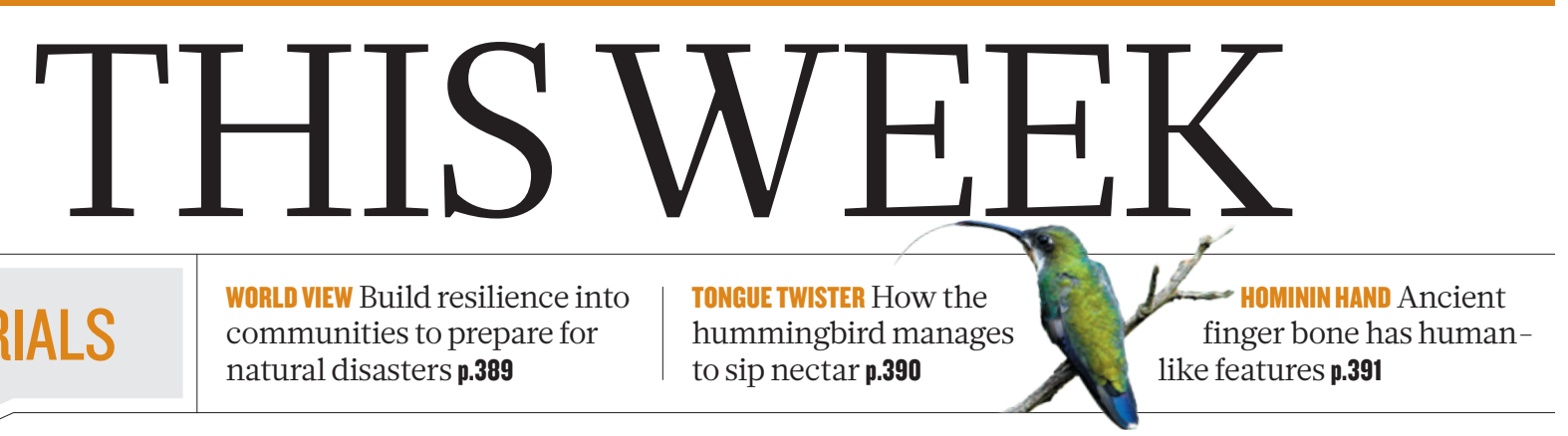

\title{
FDA vulnerability revealed
}

\section{A politically charged advisory committee meeting may have tipped the scales in favour of a mildly effective female libido drug.}

$\mathrm{L}$ oud applause erupted when an advisory panel recommended in early June that the US Food and Drug Administration (FDA) approve the first medication to treat low libido in women. Many more must have cheered when the FDA followed the committee's advice and approved the prescription drug, which will go by the name Addyi, on 18 August.

The decision comes as the FDA faces greater pressure to approve more drugs, especially for conditions that lack other treatments. The agency has accepted $89 \%$ of applications for new drug approvals so far this year compared with a rate of $50 \%$ in 2008 , according to an analysis commissioned by Forbes. Legislation in the US Congress - the 21st Century Cures Act - could encourage even more approvals. The FDA is also receiving more input from patients to gather perspectives on their diseases and available treatments. In October 2014, for instance, it convened a two-day public meeting on female sexual dysfunction, which Addyi (flibanserin) aims to address.

But critics say that previous accusations that the FDA is biased against women had more influence on the drug's approval than did the data on its safety and efficacy. They blame a coalition of non-profit organizations and drug companies called Even The Score - which includes Sprout Pharmaceuticals, the maker of Addyi - for leading a campaign that made approval an issue of gender equality. One of the group's slogans highlighted a count of the number of drugs available to treat sexual problems in men versus women: 26 to 0 .

Addyi was found to be only modestly effective in improving female sexual desire during clinical trials. On average, women taking it reported having from 0.5 to 1 additional satisfying sexual experiences per month, compared with a group taking a placebo. Participants also reported slightly higher levels of desire and slightly lower levels of distress. Small as such benefits may be, they should not be dismissed.

At the June meeting, the FDA rejected the idea that it had a gender bias. It also warned that rare sudden drops in blood pressure and a poorly understood interaction with alcohol are outstanding concerns for Addyi. Incredibly, Sprout's alcohol-interaction study included 23 men and only 2 women. As part of its approval, the FDA is requiring Sprout - which Canadian drug maker Valeant bought for US $\$ 1$ billion two days after Addyi's approval — to run three more studies on alcohol interaction after the drug goes on sale.

The vote of approval came after impassioned testimony from women who had taken the drug in trials, physicians who could offer no good alternatives to patients, and women who had experienced low libido for decades. The drug's supporters pointed to an unmet need for treatment options and said that it is only fair to have a choice about whether or not to take the drug. These points seemed to resonate with the advisory committee, which intimated reluctant support: one member who voted 'yes' noted that if Addyi were "the seventh drug in the class, it would be a very different discussion".

Many complain that the FDA acts either too fast or too slow. With ever more ways for new drugs to be approved, the agency will be expected to make more decisions more quickly. Addyi's approval reflects and encourages a trend of increased pressures from targeted campaigns. The agency and its committees will need resilience to ensure that such pressures do not overwhelm evidence-based caution.

\section{Heroism in Syria}

\section{A tribute to scholars of extraordinary courage.}

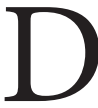
uring the Second World War, a group of historians, curators and professors risked life and limb to protect Europe's art and culture from Nazi plunderers. It is because of these 'monuments men' and women that future generations can appreciate works such as Michelangelo's sculpture Madonna of Bruges, Johannes Vermeer's painting The Astronomer and countless others.

The murder of the Syrian archaeologist Khaled al-Asaad last week is a brutal reminder of the risks that professionals have taken to protect the world's cultural heritage. Al-Asaad was known as 'Mr Palmyra' for his more than 40 years of work at that Roman Empire site in Syria. It is now occupied by Islamist militants, who last Sunday destroyed one of its temples. Al-Asaad was killed in part because he would not reveal the location of hidden artefacts, according to news reports. A week before, museum official Qasem Abdullah Yehiya was killed in a rocket attack on the Damascus Citadel and the National Museum of Damascus.

Across Syria and Iraq, a new generation of cultural guardians are risking their lives to safeguard museums, archaeological and other cultural sites from destruction and to document the damage. Their task is enormous. The destruction by Islamist terrorist group ISIS of sites such as the ancient Assyrian city of Nimrud has commanded most headlines, but its embrace of organized looting is just as great a threat. The collapse of civil society in Syria and Iraq has left hundreds of archaeological sites unguarded and susceptible to looting, encroachment and neglect.

Most of the protection efforts are necessarily secretive, but the stories that have emerged are truly heroic. Earlier this year, a group of Syrian professionals and volunteers secured a collection of Roman and Byzantine mosaics from the third to sixth centuries AD at the Maarra Mosaic Museum, near Aleppo, Syria. In February, The Wall Street Journal profiled a secretive band of Syrian academics who catalogue archaeological sites and track looted artefacts, sometimes donning disguises.

All of us who find inspiration in the cultural history of humanity, now and in the future, owe a huge debt to the sacrifices of these people. 